\title{
Biphasic Positive Airway Pressure
}

National Cancer Institute

\section{Source}

National Cancer Institute. Biphasic Positive Airway Pressure. NCI Thesaurus. Code C124039.

A form of non-invasive mechanical pressure support ventilation that uses a time-cycled change of the applied positive airway pressure level to support spontaneous breathing activity. 